\title{
Shifting the Library Paradigm: The Role of Cultural Intelligence on Tomorrow
}

by David Turnbull, David Wescombe-Down, Oksana Feklistova, Katrina Dal Lago

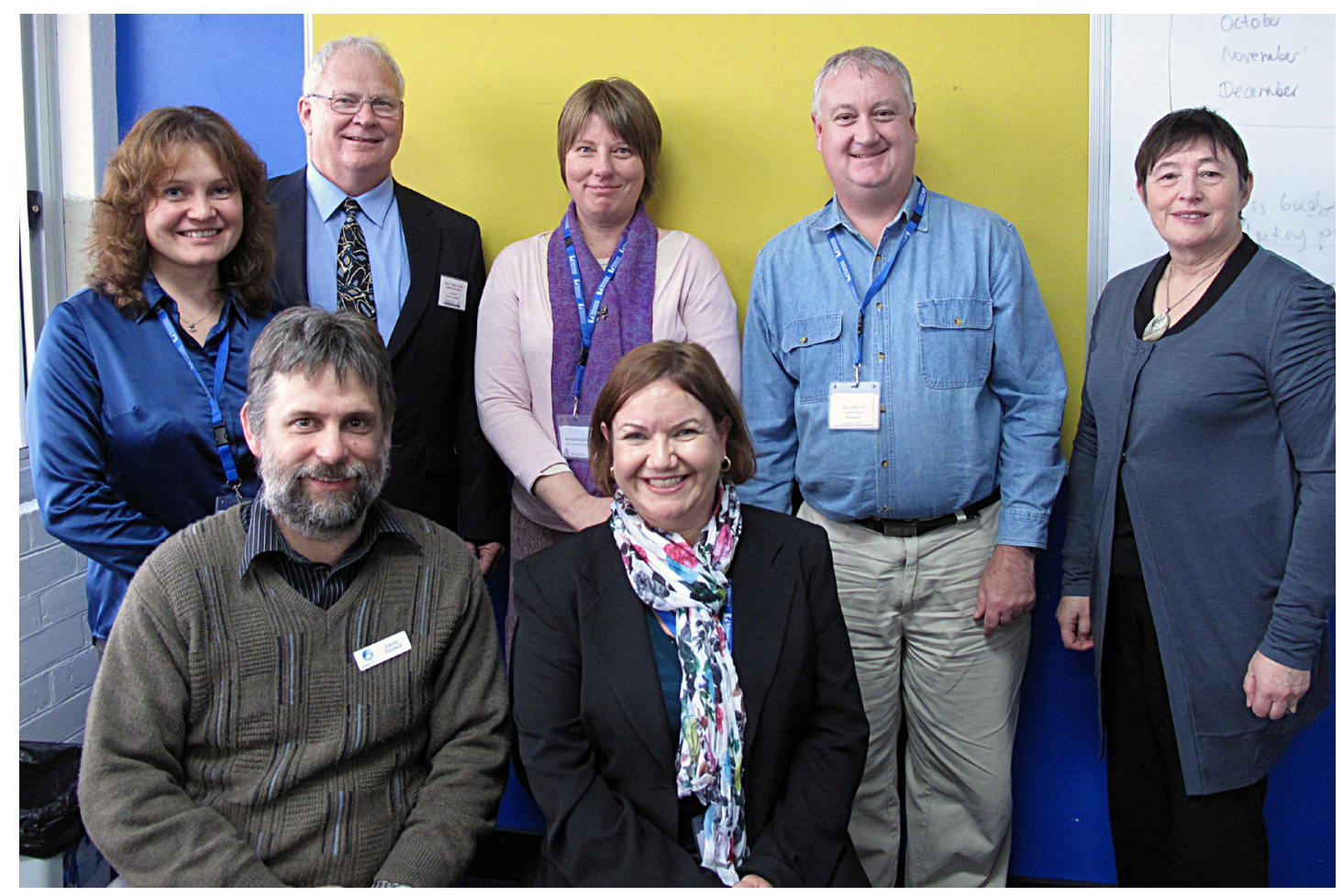

back row Oksana Feklistova, David Wescombe-Downs, Katrina Dal Lago, Gavin Glenn, Judith Bright front row David Turnbull, Helen Gorzkowski

7 his paper explores the role of cultural intelligence within libraries. Presentations were given by David Turnbull and David Wescombe-Down. David Turnbull defined culture

1 and cultural change and discussed the importance of cultural intelligence for theological librarians. David Wescombe-Down continued the discussion and focused on the importance of coping with change and the need for effective communication to manage change correctly within an organization. To gain an understanding of cultural intelligence within a library setting, Oksana 
Feklistova and Katrina Dal Lago, facilitated a discussion with conference participants using case studies relating to generational and technological change and consumer culture. The participants discussed the case studies in small groups and answers were shared amongst all participants. To explore the ethnic perspective of multiculturalism, Gavin Glenn from Camden Theological Library in New South Wales, and Judith Bright from John Kinder Theological Library in New Zealand discussed their experiences within the context of their libraries.

\section{Introduction}

Shifting the Library Paradigm: The Role of Cultural Intelligence on Tomorrow arose from discussions held between library and academic staff of Tabor Adelaide. The initial focus was on the impact of generational and technological changes on library services at Tabor Adelaide. However, as time progressed we diverged from looking at the issue from an insular, Tabor Adelaide perspective and began to ask ourselves questions such as, how do other theological libraries cope with cultural changes?, and how can our library effectively deal with change to meet the needs of our changing clientele?

\section{Presentations}

\section{David Turnbull, Cert IV TAA, Dip Ed, BA, Dip Missiology, B. Th, MA}

\section{Introduction}

My own cross-cultural journey has provided the background to this session. Firstly, living and working in Nigeria for a year, has shaped my paradigm for life as I had to thrive rather than survive in this different cultural context. At Gindiri College of Theology I had to make many adjustments to my lecturing style even though it was at degree level. I couldn't do small groups and classroom discussions as they expected a rote learning style. As English was their third or fourth language I had to keep the language functional. Use of narrative and drama became important.

Secondly, being involved in missional and cultural education in Christian higher education institutions in South Australia for the past fifteen years has caused me to reflect and apply the lessons from my Nigerian experience to the Australian context.

Therefore I am keen to help and assist Christians to be empowered to develop a cultural paradigm alongside their ministry, spirituality and theological paradigms, and adjust to the Australian cultural context with all its diversity. So I want to start a conversation, to help you in this area.

\section{Changing Cultural Context}

The Australian context is changing. Many of you will have seen and experienced the dramatic change in Australia in the last forty years with the impact of globalization, postcolonialism and postmodernism. A significant trigger event was the election of the Whitlam Government in 1972 and the way they contributed to the demise of the White Australia policy and assimilation, and gave birth to the concept of multiculturalism.

We are living and working in a multicultural society and it is not just about ethnicity. It is about gender, socio-economics, generations, climatic groupings, organizations, abilities, religious traditions, areas of interest and sexuality. Therefore, we constantly have to engage with people who are different to ourselves.

Theological college libraries are a location where these cultural dynamics are at play and are affecting the functions and services offered. The publishing industry is affected too. These cultural dynamics can cause fear, angst, panic, stress and concern. They become threats rather than opportunities. Many of the problems facing the library community have a cultural dimension. This can cause us to be overwhelmed, critical and judgmental. This is connected 


\section{"Many of the}

problems facing the

library community

have a cultural

dimension. This

can cause us to

be overwhelmed,

critical and

judgmental." to a culture shock reaction similar to, but not as extreme as, people travelling overseas. Culture shock occurs where there is uncertainty.

If not addressed, then you can become a backwater and marooned, marginalized and isolated from mainstream trends. There are numerous examples of such outcomes in the commercial, religious and educational world.

There is the need to cross the cultural chasms and manage the differences from our own cultural background. Managing difference when crossing any 'border' requires intercultural effectiveness, being contextual as Paul was when in Athens (Acts 17), and intentionality. This leads to the ability to thrive and not just survive in your context, and to turn these often perceived threats into opportunities.

Cultural Intelligence (CQ)

For such a response to difference to occur, Cultural Intelligence is required. This concept has been developed in the past decade within the business world and is relevant to any vocation/profession. ${ }^{1}$ It is defined as "the capability to function effectively across various cultural contexts (national, ethnic, organizational, generational, etc.)."2

Charles Kraft defines culture as "a complex, integrated coping mechanism, belonging to and operated by a society (social group), consisting of concepts and behaviour that are patterned and learned; underlying perspectives (worldview); resulting products, both nonmaterial (customs, rituals) and material (artefacts)." ${ }^{3}$ It can be depicted visually by an iceberg ${ }^{4}$ or a set of concentric circles with worldview in the centre, followed by belief, values and behaviour. ${ }^{5}$

To display cultural intelligence and function effectively across different cultures/coping mechanisms, four key areas of cultural intelligence need to be developed. ${ }^{6}$

- CQDrive refers to the motivation and confidence to cross borders, to adapt and to persist when the going gets tough.

- CQKnowledge refers to the knowledge that people are different and how, and the way to manage the issues that arise when engaging cross-culturally.

- CQStrategy refers to the ability to make sense of culturally diverse experiences and help plan for the engagement.

1 For resources and greater detail, visit the Cultural Intelligence Center's website http://www.culturalq.com/

2 Soon Ang and Linn Van Dyne, "Conceptualization of Cultural Intelligence"

in Handbook of Cultural Intelligence: Theory, Measurement, and Applications

(Armonk, New York: M. E. Sharpe, 2008), 3.

3 Charles Kraft, Anthropology for Christian Witness (Maryknoll, New York: Orbis Books, 1996), 38.

4 Edward T. Hall, Beyond Culture (New York: Anchor Books, 1976).

5 Lloyd E. Kwast, "Understanding Culture," in Perspectives on the World

Christian Movement: A Reader (eds. Ralph D. Winter and Steven C. Hawthorne:

Pasadena, California: William Carey Library, 1981), 361-364.

6 David Livermore, Leading with Cultural Intelligence: The New Secret to Success

(New York: American Management Association, 2010), chs. 2-7. 
"he results of

becoming culturally

intelligent can be

positive and varied.

Some benefits

include smooth

cross-cultural

adjustment, an

improved sense of

personal well-being

when in a cross-

cultural context, and

an increase in job

performance."
- CQAction refers to the behaviour and capabilities to change verbal and non-verbal understanding to fit.

Therefore an individual or organization, through developing cultural intelligence can display positive attributes, think grey, tolerate ambiguity and suspend judgment. ${ }^{7}$

Advantages of Improved Cultural Intelligence

Cultural intelligence can be measured through a self-report instrument. The results can range from being rather low where a person reacts to the external stimuli to rather high where a person automatically adjusts.

The results of becoming culturally intelligent can be positive and varied. Some benefits include smooth cross-cultural adjustment, an improved sense of personal well-being when in a cross-cultural context, and an increase in job performance. ${ }^{8}$

Therefore, there are many advantages for theological librarians in the contemporary workplace. These include:

- Understanding and appreciating others who are different.

- Exegeting cultures for contextualization.

- Seeing the world from multiple perspectives.

- Improving communication.

- Leading to creative initiatives.

- Managing cultural conflict and stress.

\section{Conclusion}

I encourage you to develop your cultural paradigm so you can be empowered to respond to the cultural challenges that are relevant to your context. It does require a long-term perspective. You can start by reading more on the subject and there are plenty of ways to develop cultural intelligence.

There are consequences at both a personal and organizational level if cultural intelligence skills and knowledge are not developed.

David Wescombe Down will explore ways to manage changes that can occur, methods to develop cultural intelligence and look at some of the cultural challenges facing theological college libraries.

David Wescombe-Down, PhD, ScEdD, M.Ed (Educational Psychology),M.Sc.(Human Movement),M.Ed.(Middle Schooling)

Change is upon us. Without change we will stagnate, so change is both desirable and necessary. Nobody will say that it is a comfortable, pleasant experience, always clearly communicated or always clearly understood. From an educational perspective, examples of change include the following:

- Global change - learning is mobile \& ICT-based

- Sector change - roles of library/resource centre staff

- Delivery change - roles of academics \& teachers

- Discipline change - undergraduate \& postgraduate at all levels

7 Duane Elmer, Cross-Cultural Servanthood: Serving the World in Christlike

Humility (Downers Grove, Illinois: InterVarsity Press, 2006), 50-55.

8 Livermore, Leading with Cultural Intelligence, ch. 8 
- Educational space change - wireless, BYO devices \& the future of computing rooms/suites (Fgure 1).

I see the nature of change for ANZTLA members may involve a process that impacts the entire knowledge sector, of which we are part. One reason for any lack of understanding regarding the need for change is often caused by ineffective communication. Communication is the number one issue in every change process, in every workplace, and in every country. What we are trying to do today is communicate effectively. For that to eventuate, everyone present needs to actively participate. "Change" is not a spectator sport! Please be active, not reactive. Remember, "Learning organizations are those that emphasize mental flexibility, team learning, a shared vision, complex thinking, and personal mastery. It is proposed that learning organizations can be promoted through participation and dialogue in the workplace. ${ }^{9}$

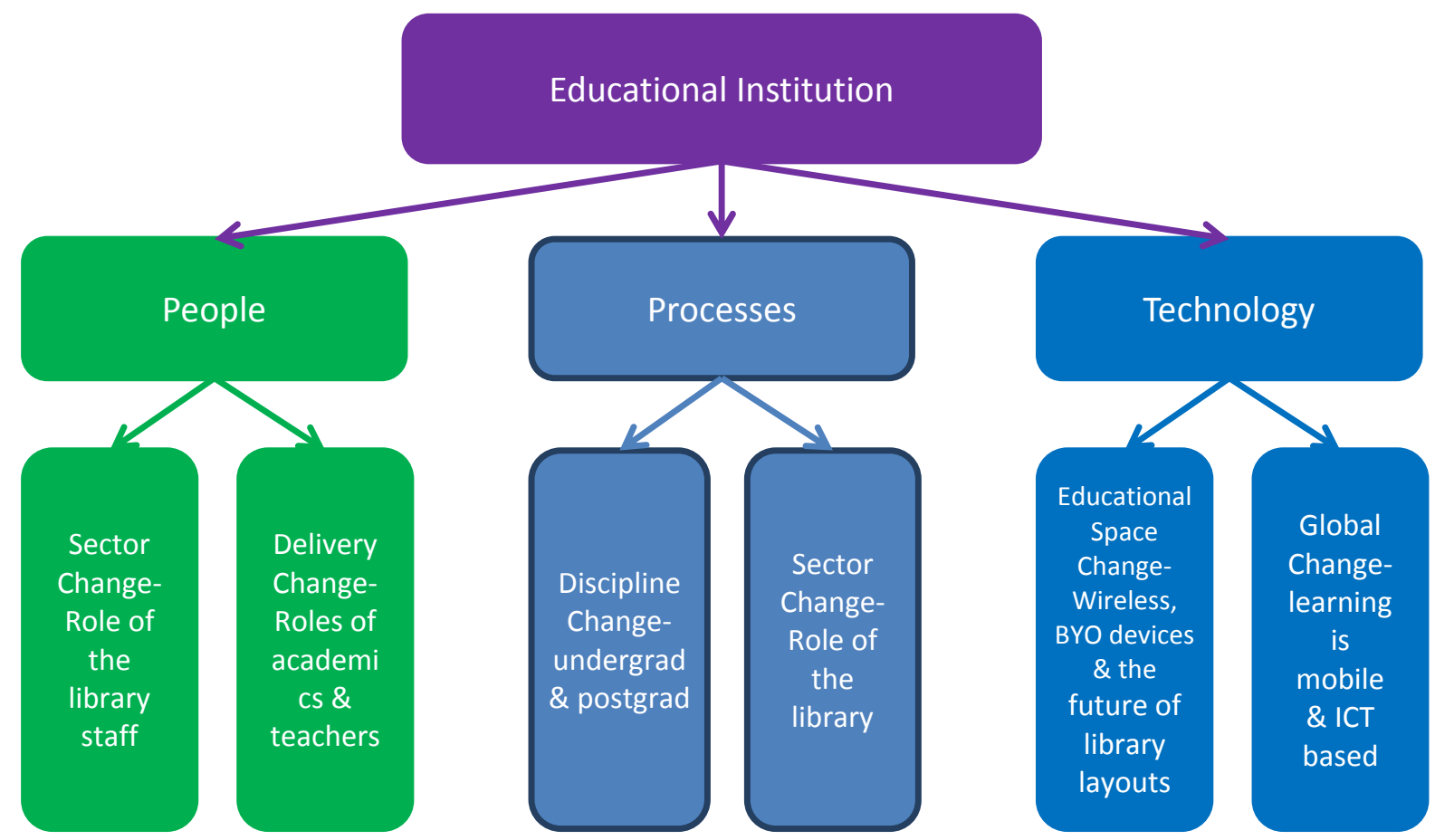

Figure 1. A diagram showing potential areas of change within an educational institution.

If any part of the Knowledge Landscape is not flexible or willing/able to accommodate the changes required, the "big picture" landscape will continue to evolve dynamically ('move on'), and will remain sustainable. However, any inflexible element (you, me??) may result in our own setting becoming non-sustainable, resulting in:

- Operational reductions

- Closures

- Job losses

- Institutional 'evaporation'

If not, today is an opportunity to "X-ray" ANZTLA, its member institutions, and the staff involved.

We need to monitor what we are actually doing and how well we are aligned with our home institutions' strategic plans or strategic directions.

Beliefs, values and change...

Perhaps we also need to review our beliefs and values regarding 'change', particularly with respect to the emergent knowledge landscape changes, since faith, beliefs and values form our attitude, and attitude generates our behaviour. It is our behaviour that drives our responsive or reactionary decision-making, and THEY are what will determine our future.

9 Katherine Miller, Organizational Communication: Approaches and Processes (Belmont, CA: Thomson/Wadsworth, 2006). 


\section{"The aim was}

to encourage

participants to

think about cultural

intelligence and raise

awareness towards

attitudes which may

impact on delivering

library services in a

culturally intelligent

manner."
So in 2013, for this conference \& beyond, we are looking to reenergise, regroup \& refocus by revisiting our thoughts and opinions about the 'big picture', the image or perception of our own library or resource centre and our roles within it and our association.

\section{Case Studies}

Oksana Feklistova, B.Phil.(Hons), B.Ed, GradDip Information Management;

Katrina Dal Lago, BA(Hons), Grad Dip Lib \& Info Services

Three case studies were given to small groups of conference participants for group discussion. Although the case studies varied, the questions for discussion were the same:

- List the challenges you see arising? Identify the key one.

- What needs to change?

- How do you plan to address these changes?

- How will you manage the implementation of this change?

The purpose of the discussions was not to provide 'right' or 'wrong' answers and ready solutions. The aim was to encourage participants to think about cultural intelligence and raise awareness towards attitudes which may impact on delivering library services in a culturally intelligent manner.

Below are the case studies discussed and the key findings raised.

Technological case study ${ }^{10}$

The College is shifting to a blended learning model with online resources. Academic Heads asked the Library to support the move. Library is responding to pressure by giving preference to purchasing e-textbooks, $e$-books and e-journals rather than printed versions. The Library Manager is concerned about purchasing arrangements, staff and student access via $L M S$, the technological shift and divide.

Issue

This case study reflects a situation currently experienced by library staff at Tabor Adelaide's academic library, although we believe we are not alone and this issue may also be affecting an increasing number of ANZTLA members. Tabor Adelaide would benefit greatly from implementing e-books into its collection. Firstly, space is at a premium, library bays are already at capacity and there are no plans to extend the building. Secondly, a large proportion of our

10 To understand this case study further, you may like to consult the following sources: Vicky McDonald, "From Paper Repositories to 21st Century Learning Environments,” (Brisbane, QLD: QUT, 2012), http://www.ifla.org/files /assets/library-buildings-and-equipment/Conferences/Session\%202b\% 20-\%20McDonald\%20-\%20Creatingthe\%2021st\%20century\%20learning\%20 environment.pdf ; Joe Murphy, "Technology and Innovations in Libraries and Their Impact on Learning, Research and Users," Proceedings of the IATUL Conferences, Paper 47 (2012), http://docs.lib.purdue.edu/iatul/2012/papers/47. 
"The phrase "no, Kindle e-books

cannot be purchased because they are sold

to one person and

are not borrowable'

became a common

one in our library

as we responded to

many academics

requests to purchase

e-books from

Amazon." students are external, and they would benefit from the availability of additional electronic resources. From Tabor Adelaide's perspective, one of the biggest issues involved clarifying to academics that not all e-books are created equal. The phrase "no, Kindle e-books cannot be purchased because they are sold to one person and are not borrowable" became a common one in our library as we responded to many academics requests to purchase e-books from Amazon. Implementing authentication software is also another factor to be considered. To allow easy access for remote users, authentication software needs to be installed, which is a slow process as we have one IT support technician for the whole college.

\section{CQResponse}

At this stage there is not one tangible solution. While academics are digitizing readings and making them available to students online, the library has begun to slowly, slowly expand the e-book collection. We have begun purchasing from EBL as well as Cambridge Online. Communicating with lecturers is also an important aspect of the e-book transition process. We are planning to run a training session for staff to raise awareness of the e-book's potential and most importantly, the differences which exist between e-book publishers and the limitations of certain providers such as Kindle.

The ANZTLA Conference group discussion identified the following questions as priorities to be addressed:

- Libraries need to participate in where decisions are made on management level

- Financial issues - what is the budget?

- Lots of conversations are required with the whole team

- Training / the correct software

- The institution must acknowledge the library manager \& address the issues seriously

\section{Consumer culture expectations case study ${ }^{11}$}

Funding cuts require your library to change its operating practices to better align with consumer expectations. A survey of staff and students revealed differences between students' expectations of the libraries and information accessibility and the library staff members' expectations from students.

11 To understand this case study further, you may like to consult the following source: Jane Fletcher, "Breaking Down the Barriers - The No Desk Academic Library," (Sydney: University of New South Wales, 2011), http://www.ifla.org /files/assets/library-buildings-and-equipment/Conferences/Session\%203b\% 20-\%20Fletcher\%20-\%20Breaking\%20down\%20the\%20barriers.pdf. 
Issue

\begin{tabular}{|c|c|}
\hline Student expectations of the library & Staff expectations of students \\
\hline $\begin{array}{l}\text { The reference librarian will search the } \\
\text { catalogue to find relevant resources. }\end{array}$ & $\begin{array}{l}\text { Students are expected to search the catalogue } \\
\text { and ask for help when they experience difficulty. }\end{array}$ \\
\hline $\begin{array}{l}\text { Librarian is available at short notice to } \\
\text { provide database training when needed. }\end{array}$ & $\begin{array}{l}\text { Expect students to attend information } \\
\text { literacy sessions arranged by the library during } \\
\text { the academic term. }\end{array}$ \\
\hline $\begin{array}{l}\text { Library is a place to meet and have group } \\
\text { discussions. }\end{array}$ & Students use the library to study quietly. \\
\hline $\begin{array}{l}\text { Books and services are available when they } \\
\text { need them. }\end{array}$ & $\begin{array}{l}\text { If a core text book is required, the students } \\
\text { should have their own copy. }\end{array}$ \\
\hline $\begin{array}{l}\text { Expect their individual and immediate needs } \\
\text { to be met. }\end{array}$ & $\begin{array}{l}\text { Expect student to adhere to rules to deliver } \\
\text { consistency in library services for all users. }\end{array}$ \\
\hline $\begin{array}{l}\text { Expect that the LMS is easy to use (Google- } \\
\text { like) and will deliver relevant results quickly. }\end{array}$ & $\begin{array}{l}\text { Expect students to spend time searching to } \\
\text { find a broad range of resources. }\end{array}$ \\
\hline $\begin{array}{l}\text { Expect the library will be open over extended } \\
\text { periods which suit their busy lives. }\end{array}$ & $\begin{array}{l}\text { Realise students are busy however they should } \\
\text { be able to come in during the } 9-6 \text {, Mon - Fri } \\
\text { hours set by library. }\end{array}$ \\
\hline
\end{tabular}

CQResponse

At Tabor Adelaide Library we have begun to redefine how the library space and services are used by the students. Traditionally the Library has had just one reading space. We have recently created several new attractive group study spaces with whiteboards and computers, laptop bars with powerpoints and wireless internet access and individual study desks.

The library hosts several social events throughout the year, in order to engage students and staff in creating a rich and enjoyable learning environment and developing a sense of community within Tabor.

There is now a Student Help Desk available in the library. It is staffed by postgraduate students who assist undergraduate students with their study and research queries. Rather than forcing students into the fixed-schedule training programs, library staff have developed flexible training delivery strategies. There are opportunities for students to book a session on-demand, do self-training by watching short interactive help videos, and/or receive oneon-one assistance from a Librarian or Student Help Desk Officer.

The key Library strategy over the next few years, is to increase the number of electronic resources and enhance off-campus users' access to them. Approaches such as purchasing a new cutting-edge library management system and developing a single sign-on system are just a few ways of achieving this aim.

The ANZTLA Conference group discussion identified the following questions as priorities to be addressed:

- Communication

- Expectations

- Balance

- Do academic staff promote the library?

- Library committees are required so there can be a balance of staff/students/academics - it is the ideal forum as it is structured

- Need to narrow the chasm - foresee barriers, partnership with other institutions

- Be realistic - what can we communicate

- No one minds being told no if they are told why...

- Use of surveys. Share the data of surveys between library-students-staff

- Manage expectations 


\section{"A lecturer of a} mixed generation class prescribes a required resource which is placed in a high demand short-term loan library collection. The mid semester borrowing history report revealed that no Gen Y students had accessed the resource."

\section{Generational case study ${ }^{12}$}

A lecturer of a mixed generation class prescribes a required resource which is placed in a high demand short-term loan library collection. The mid semester borrowing history report revealed that no Gen Y students had accessed the resource.

Issue

This situation occurred at Tabor Adelaide. In regard to this situation a lecturer was concerned that many students in his class had not accessed any of the recommended reading texts in the subject outline. The library staff tried to identify the reasons behind it.

\section{CQResponse}

Rather than being judgemental and making assumptions regarding the behaviour of the students, library staff responded by first checking the history of the items to see how many of them had been borrowed. The librarian offered to visit the class during the next scheduled lesson and provide an information literacy session for the students.

During the information literacy session the librarian also took the books to class to increase student awareness and also provide an opportunity for the students to borrow the books if they chose to do so. Rather than assume the students had not read the texts, they were asked questions to clarify whether they had already purchased their own copy or read the books in the library. Only two of the students had either read or purchased the books. The students were also given a demonstration on using the subscription-based electronic resources available at Tabor Adelaide, and a session on the importance of recognising quality academic sources on the web. The session was received positively, however, no students took up the offer of borrowing the books demonstrated in the session. The reluctance on the students' part to borrow the books was not explored further. Library staff felt this was the responsibility of the lecturer to pursue as there may have been another reason the students were not accessing the materials.

One of the core issues identified by the ANZTLA Conference group in regards to this case study was communication between a lecturer and librarian. Library staff members have to recognise and examine the problem of students not being able to access the titles. Is it due to the differences in expectations and preferences between Gen $\mathrm{X}$ and $\mathrm{Y}$ ?

Ethnic perspective

For the overview of how the Camden Theological Library in New South Wales and John Kinder Theological Library in New Zealand

12 To understand this case study further, you may like to consult the following source: Martin Halbert, Carrie Finegan, Katherine Skinner, "Free Culture and the Digital Library Symposium Proceedings 2005," http://digital.library.unt.edu /ark:/67531/metadc97947/. 
"The technological, consumer culture

expectations and

generational

\section{case studies}

were discussed

by the audience

with a view of

facilitating sharing

of experiences and

expertise. Reports

from the case

studies highlighted

the importance of

communication, positive attribution

and research of

behaviour and

expectations." respond to the needs of their ethnically diverse clientele, please see the presentations from Gavin Glenn and Judith Bright, below.

Conclusion

The presentation has introduced the cultural paradigm concept, and its importance in the process of managing change facing theological libraries in the 21st century. It was emphasized how crucial it is to understand differences and develop appropriate skills in libraries to empower them to move forward rather than remain static.

The audience was presented with several issues that theological libraries may face that have a cultural dimension and therefore need the cultural paradigm in dealing with them. The technological, consumer culture expectations and generational case studies were discussed by the audience with a view of facilitating sharing of experiences and expertise. Reports from the case studies highlighted the importance of communication, positive attribution and research of behaviour and expectations.

Let the conversation continue!

\section{Bibliography}

Ang, Soon and Linn Van Dyne. "Conceptualization of Cultural Intelligence." In Handbook of Cultural Intelligence: Theory, Measurement, and Applications. Armonk, NY: M. E. Sharpe, 2008.

Elmer, Duane. Cross-Cultural Servanthood: Serving the World in Christlike Humility. Downers Grove, IL: InterVarsity Press, 2006.

Fletcher,Jane. "Breaking Down the Barriers-The No Desk Academic Library”. Sydney: University of New South Wales, 2011. http:// www.ifla.org/files/assets/library-buildings-and-equipment /Conferences/Session\%203b\%20-\%20Fletcher\%20-\%20 Breaking\%20down\%20the\%20barriers.pdf.

Halbert, Martin, Carrie Finegan, Katherine Skinner. "Free Culture and the Digital Library Symposium Proceedings 2005.” http:// digital.library.unt.edu/ark:/67531/metadc97947/.

Hall, Edward T. Beyond Culture. New York, NY: Anchor Books, 1976.

Kraft, Charles. Anthropology for Christian Witness. Maryknoll, NY: Orbis Books, 1996.

Kwast, Lloyd E. “Understanding Culture."In Perspectives on the World Christian Movement: A Reader, edited by Ralph D. Winter and Steven C. Hawthorne. Pasadena, CA: William Carey Library, 1981.

Livermore, David. Leading with Cultural Intelligence: The New Secret to Success. New York, NY: American Management Association, 2010. 
McDonald, Vicky. "From Paper Repositories to 21st Century Learning Environments." (Brisbane, QLD: QUT, 2012). http:// www.ifla.org/files/assets/library-buildings-and-equipment /Conferences/Session\%202b\%20-\%20McDonald\%20-\%20 Creatingthe\%2021st\%20century\%20learning\%20environment .pdf.

Miller, Katherine. Organizational Communication: Approaches and Processes. Belmont, CA: Thomson/Wadsworth, 2006.

Murphy, Joe. "Technology and Innovations in Libraries and Their Impact on Learning, Research and Users." Proceedings of the IATUL Conferences. Paper 47 (2012). http://docs.lib.purdue.edu /iatul/2012/papers/47. 